\title{
The Value of \\ Incidental Learning in a Multidisciplinary Setting
}

Ross Hyams ${ }^{1}$

Faculty of Law,

Monash University,

Clayton Campus

Wellington Road,

Victoria, 3800

Australia
Denise Sadique ${ }^{2}$

Department of Social Work

Faculty of Medicine,

Nursing and Health Sciences

Monash University

Caulfield Campus,

Sir John Monash Drive,

Victoria, 3145

Australia

1 Ross Hyams is a practicing lawyer and Senior Lecturer-in-Law in the Faculty of Law of Monash University, Melbourne, Australia

2 Denise Sadique is a Social Work Student Unit Supervisor, Tutor and Field Education Assistant in the Department of Social Work, Monash University 


\section{Introduction}

There is much to be gained by students learning together in a multidisciplinary environment. Enabling students to interact in a multidisciplinary clinical setting enhances their opportunity to learn from each other, their supervisors from different disciplines and from their experiences with clients. As well as "formal" learning opportunities which take place in the classroom, seminar environment, or in one-to-one instruction with a clinical supervisor, students working in a clinical setting have a range of opportunities to be exposed to informal, or incidental learning. This is learning that occurs in an opportunistic, unplanned and often, serendipitous fashion. This paper reflects on incidental learning opportunities that have been observed to take place in a multidisciplinary clinical setting, specifically between law, social work and business students. These reflections come directly from practice experience at the Monash-Oakleigh Legal Service, operated by the Faculty of Law at Monash University in Melbourne, Australia.

Originally established as a pilot project in 2010, the multidisciplinary clinic runs two client intake sessions per week throughout the year, involving approximately 65 students from three disciplines on a yearly basis. The students interview clients in a team (law, social work and finance) and the supervisors also sit together as a team to advise the students. The Legal Service has a generalist practice, dealing with a diverse range of matters such as car accidents, crime, family law, debt, neighbour dispute and traffic infringements. Since its inception, students graduating from the clinic, and their supervisors, have been surveyed about their views regarding their participation in multidisciplinary clinical education. Accordingly, one of the main themes that has emerged from these surveys is that students are learning a great deal that supervisors are not necessarily directly teaching them- that is, much "incidental" learning is taking place from the cross-fertilisation between students and supervisors of different disciplines, during the clinical experience at the Legal Service. There was also incidental learning that took place among the supervisors of the different disciplines, with supervisors stating that they gained knowledge and insights into each other's disciplines. These were both unexpected outcome of the multidisciplinary clinical methodology, but outcomes which are much welcomed by clinical educators.

This paper will first attempt to define and describe incidental learning. It will then focus on the opportunities for incidental learning which can arise in a multidisciplinary clinical setting, concentrating on both formal and informal learning outcomes and will ask whether such outcomes can be measured and if so, how. Ultimately, it will be concluded that much insight and wisdomtakes place by incidental learning in a multidisciplinary clinical environment and that we should seek to create and maintain a work environment that nurtures this type of learning. Accordingly, recommendations will be made for future clinical education which may be able to capitalise on and nurture collaboration, transfer of learning and informal learning opportunities to provide participating students from diverse disciplines with skills and knowledge that better prepare them for the reality of the workforce. 


\section{What is incidental learning?}

Garrick $^{3}$ provides a literature review that offers various definitions of incidental learning. A starting point in defining the concept may be to investigate what formal learning consists of by way of comparison. Tusting ${ }^{4}$ states that formal learning comprises the following characteristics:

- It takes place in an educational institution.

- It follows a planned curriculum which has been set in advance.

- It is accredited using formal means of assessment.

- Teaching is delivered by way of a hierarchical relationship between teacher and student. ${ }^{5}$

By comparison, incidental learning is described by Garrick as, amongst other descriptors, nonintentional, self-directed, experiential, contextual and reflective. ${ }^{6}$ In a clinical environment, some experiential, contextual and reflective learning outcomes are intentional on the part of the educator. Part of the objective of clinical legal education is to intentionally attempt to enable the student to learn from experience and discover, for example, the appropriate role of a professional. In addition to intentional learning experiences, clinic creates an environment which also offers serendipity - learning can take place in a spontaneous fashion when you least expect it, often in situations that a teacher would find very difficult to simulate in most classroom situations. However, the opportunities for incidental learning will often depend on the learning environment that has been created. A formal classroom or lecture theatre environment may not be fertile ground for spontaneous and reflective learning amongst students. An appropriate "climate" must occur in which the need, motivation and opportunity for learning exist. ${ }^{7}$ Marsick and Watkins describe this climate as simply one of context - that is, incidental learning can come as a result of everyday encounters where a challenge arises or a problem must be resolved. ${ }^{8}$ Further, in their study of managerial proficiency reported in $2003,{ }^{9}$ Enos, Kehrhahn and Bell discovered that managers consistently reported that their learning of core managerial skills arose mostly from informal, or incidental, learning opportunities. ${ }^{10}$ This indicates that incidental learning has a key role to play in transfer of learning - that is, how a trainee applies skills learned in their training to a variety of situations required in the work environment. ${ }^{11}$

Arguably, the context requirement described by Marsick and Watkins is unlikely to arise in formal learning environments and most likely to take place in the context of a clinic - where clients' problems must be resolved and their needs addressed on an everyday basis. This is why

3 J Garrick (1998) Informal Learning in the Workplace: Unmasking Human Resource Development.London: Routledge

4 K Tusting (2003) "Working Paper No 2: A Review of Theories of Informal Learning" Literacy Research Centre, Lancaster University, UK

5 Ibid 6

6 Ibid 5.

7 V Marsick \& K Watkins (2001) 'Informal and Incidental Learning' 89 New Directions for Adult and Continuing Education 25 at 28.

8 Ibid 29.

9 M Enos, M Kehrhahn \&A Bell (2003) 'Informal Learning And The Transfer Of Learning: How Managers Develop Proficiency' 14 (4) Human Resource Development Quarterly 369

10 Ibid 377.

11 Ibid 371. 
clinical education is such a fertile ground for incidental learning - it provides the context which forms the central hub of Marsick and Watkins informal and incidental learning model.

Students consistently complain that classroom learning of doctrine has little to do with, or is difficult to apply to, real life client situations (this is especially true of law students where the majority of their legal education has been traditional lecture style). If we apply Enos, Kehrhahn and Bell's findings about managerial proficiency to university students, it is apparent that much of the skills and knowledge that students acquire from incidental learning can assist them in the transfer of this learning to various client situations both within the clinic and in their future professional lives.

Lave and Wenger ${ }^{12}$ point out that informal learning is a social process. It requires people to participate in interactions with others in the workplace that arise out of an integrated set of work relations. ${ }^{13}$ It cannot take place in isolation. Again, this is where clinical education really comes to the fore - by their very nature, clinics are social environments requiring students to interact with a variety of people - clients, administrative staff, supervisors and each other. This is a rich and diverse environment which cannot be replicated in a classroom setting where opportunities for informal learning are very difficult to create. Enos, Kehrhahn and Bell found that "interactions with others" was the most prevalent learning activity for new managers in the workplace, and provide a wealth of learning. ${ }^{14}$ These are important findings which underscore the value of incidental learning for university students in becoming work-ready graduates.

Important incidental learning in practice is also noted by Le Clus as learning that occurs within everyday work activities. Learning as part of experience and participation indicates that learning occurs using a variety of strategies. Making sense of daily occurrences in a workplace involves reflecting on what is known and then experienced in a self-directed way. Le Clus also suggests that incidental learning is a social process that can occur from observation, repetition, social interaction and problem solving. ${ }^{15}$ Indeed Le Clus highlights Lave and Wenger's more detailed "community of practice" idea, where activities and understandings do not exist in isolation but have meaning as part of a system of relations among persons. Learning thus involves transformation as stated by Lave and Wenger "becoming a different person" and "the construction of identities". ${ }^{16}$

Incidental learning is also described by Le Clus as most often occurring in the moment, tacit and situated within social situations and interactions with co-workers. Such an environment is available and supported in the clinical setting where the focus is service delivery and the development of students' skills and knowledge for practice. An explicit purpose of social work field placement is to allow experience to influence the developing professional self. ${ }^{17}$ Le Clus characterises tacit knowledge as "the subjective and personal knowledge acquired by individuals."

12 J Lave \& E Wenger (1991) Situated Learning: Legitimate Peripheral Learning. In R Pea \& JS Brown (Eds) Learning in Doing: Social, Cognitive and Computational Perspectives Cambridge University Press.

13 Id.

14 M Enos, M Kehrhahn \&A Bell above n 10 at 379.

15 M Le Clus (2011) 'Informal Learning in the Workplace: A Review of the Literature' (51)(2) Australian Journal of Adult Learning 355.

16 J Lave \& E Wenger (1991) Situated Learning: Legitimate Peripheral Learning. In R Pea \& JS Brown (Eds) Learning in Doing: Social, Cognitive and Computational Perspectives Cambridge University Press

17 Ching Man Lam, Hung Wong and Terry Tse Fong Leung (2007) 'An Unfinished Reflexive Journey: Social Work Students' Reflection on their Placement Experiences (37) British Journal of Social Work, 91. 
She refers to Gourlay's ${ }^{18}$ review of research studies from different disciplines that suggest tacit knowledge is personal, experiential, job specific, transferred during conversation, known or unknown to the learner and as such, is knowledge that can be learnt incidentally or informally. ${ }^{19}$ Much of this learning may be incidental to the tasks at hand, unintentional and only noticed in journal reflections or conversations with peers or supervisors. However, it may also be critical to the development of skills in learning from and through experience. ${ }^{20}$ This reflective practice can be improved by making such incidental "implicit knowledge explicit and exposed to scrutiny," according to Fook. ${ }^{21}$ It is hoped such incidental learning assists growing practitioners to be better at learning to respond and manage change, perform as required and feel satisfied with their efforts as they progress to the workplace. ${ }^{22}$

In Marsick's examination of incidental learning, it is further suggested that learning is not only implicit or incidental but more easily understood through the broader socio cultural dimension of workplace learning. The interaction of people in their "social, historical and cultural context" 23 is identified as affecting learning practices and choices, shaping and being shaped by people, not always consciously. Marsick highlights the influence "nurturing socio-cultural and organisational environments" 24 such as the context created for students in the multidisciplinary setting, has on formal and informal individual learning. Activities such as experimenting, reflection, examining practice, sharing ideas, learning by doing and making mistakes, mentoring and coaching, giving and receiving feedback as well as every day conversations with peers and supervisors are all offered as opportunities to stimulate the development of skills relevant to individual professional practice, no matter what the discipline.

Supportiveness of an environment for learning in an accidental and incidental way was highlighted during Gola's narrative research. ${ }^{25}$ Gola studied social workers in Italy, to better understand informal learning. Marsick noted that Gola identified that social workers' learning could be categorised as "deliberative learning, reactive learning and implicit learning." 26 The difficulty Gola found studying implicit learning was that even though this type of learning may be driven by values and goals that could be espoused, the learning itself may not be conscious and therefore difficult to identify. An important role of professional supervision is to assist students to identify this implicit incidental learning, as it is experienced. In the multidisciplinary learning setting, supervisors aim to

18 Gourlay,S.N (2002) 'Tacit knowledge, tacit knowing or behaving?', paper presented at the 3rd European Organisational Knowledge, Learning and Capabilities Conference, Athens, 5-6 April and Gourlay,S.N (2004) 'Knowing as semiosis: Steps towards a reconceptualisation of "tacit knowledge", in H.Tsoukas \& N. Mylonopoulos(eds.), Organisational knowledge systems, London: Palgrave MacMillan: 86-105 in MLe Clus (2011) 'Informal Learning in the Workplace: A Review of the Literature' (51)(2) Australian Journal of Adult Learning 355.

19 M Le Clus above n 16 at 365.

20 Ibid 365.

21 Jan Fook and Fiona Gardner (2001) Critical Reflection in Context: Applications in Health and Social Care (Routledge,Hoboken) 3.

22 M Le Clus above n 16 at 358.

23 Victoria J. Marsick (2009) 'Toward a unifying framework to support informal learning theory, research and practice' (21) (4) Journal of Workplace Learning, 265.

24 Ibid $274-275$

25 Ibid 271.

26 bid 281. 
encourage the development of a climate where this knowledge can be discovered. ${ }^{27}$

\section{Relevance of a multidisciplinary learning environment}

For law students, new paradigms of collaborative practice and non-adversarial methodologies in the legal system require law graduates to have a wider understanding of the lawyering roles than was previously expected. As Bratt points out, the conventional study of appellate cases, often being large scale commercial law disputes, provides an inaccurate picture of what graduates will encounter in their daily practice. ${ }^{28}$ This method of studying law also does not provide the background, the narrative or the context of law in its social milieu, which forms a large element of the setting of legal disputes in practice.

Further, as Daly notes, the increasingly complex demands of clients' legal issues demand integrated advice $^{29}$ - that is, advice from a lawyer which takes into account a variety of non-legal factors. There are also changes taking place in clients' expectations of lawyers. There is a growing belief amongst clients that lawyers must be creative and knowledgeable beyond the strict confines of the law and the legal system and that they will provide a common sense $\mathrm{e}^{30}$ approach to problem solving from a multi-faceted perspective. This expectation can also be seen in the justice system itself as more courts and judicial officers adopt collaborative practices. For example, Drug Courts adopt a therapeutic approach that attempts to resolve offenders' addiction to drugs, rather than just meting out punishments. Participation in this, and other 'problem-solving' courts, requires lawyers to collaborate with prosecutors, psychologists, therapists, support workers and other court officials. ${ }^{31}$ These types of courts require a multidisciplinary teamwork approach and a willingness to understand, and work with, professionals in other disciplines. As Freiberg points out, in a Drug Court environment such a team may be a group of legal, health, law enforcement and correctional professionals. ${ }^{32}$

It requires a range of disparate groups, with often conflicting interests, to work together. The team usually meets prior to each sitting of the drug court to review the cases and remains in court during proceedings. ${ }^{33}$

Working in a new court environment such as this means that law graduates have to take a much less adversarial view of their role in the justice system - in a criminal law context, being a zealous advocate and focusing all energies on simply aiming to acquit one's client may no longer be

27 Id.

28 Carolyn S Bratt (1977-78) 'Beyond the Law School Classroom and Clinic - A Multidisciplinary Approach to Legal Education' 13 New England Law Review 199 at 202.

29 Mary C Daly (2000) 'What the MDP Debate Can Teach Us About Law Practice in the New Millennium and the Need for Curricular Reform' 50 Journal of Legal Studies 521 at 533.

30 Ibid 543.

31 Moore D (2007 'Translating Justice and Therapy: The Drug Treatment Court Networks' (47) British Journal of Criminology 42 at 48.

32 Arie Freiberg (2002) "Drug Courts: Sentencing Responses to Drug Use and Drug-Related Crime" 27 Alternative Law Journal 282 at 284-285

33 Id. 
an appropriate course, especially in a situation where a client is a repeat offender. ${ }^{34}$ Taking a multidisciplinary approach to such a client will affect how an initial interview is conducted and the resources that are brought to bear from various other professionals in order to deal with the client's wider life issues. This is a much broader investigative and counseling role than lawyers have previously undertaken. If law students don't glean an understanding of, and some familiarity with, this enhanced lawyering role from the outset of their legal education, they will find themselves ill-equipped to provide an appropriate level of service delivery when they graduate. This new understanding can be seen in one of the early comments made in the reflective journal of a law student in the multidisciplinary clinic:

One of the most interesting events has been meeting the police prosecutor handling the criminal matter of one of my clients to negotiate a potential plea. It was surprising to find that the meeting was not adversarial. Rather, there seemed to be a common understanding of what was fair and reasonable and a real interest in working together to resolve the case in a timely manner that also considered the interests of the client.

A multidisciplinary learning environment, where students can learn from those in other disciplines in an informal setting, also assists law students to develop self-identity and autonomy as a professional. There are various choices about one's self-identity as a lawyer that can be made by law graduates. O'Grady suggests that lawyering styles can run the entire spectrum from "empathetic connection" to "detached neutrality". 35 Parker and Evans propose a paradigm of four different lawyering approaches commencing with the traditional "adversarial advocate", ${ }^{36}$ in which the lawyer sees themselves as simply having a duty to pursue the client's interests within the boundaries of legality. At the other end of the spectrum, they posit a self-identity of the lawyer as moral activist. ${ }^{37}$

Rather than simply just absorbing their new employer's paradigm of lawyering, law students can develop their own self-identity as professionals by exposure to a multidisciplinary learning environment during their undergraduate legal education. A strong self-identity will benefit the new graduate in their complicated, and often challenging, dealings with the reality of practice. Lesnick posits that law students must be confronted with "questions of identity" 38 in order to promote their professional growth and that a failure to do so sends an unspoken message that legal education is simply a tool to obtaining a well-paid job. In a multidisciplinary clinic, law students have the opportunity to test their understandings of their professional role against those of students in other disciplines, by comparing, for example, their understanding of their professional responsibilities and approach to ethical issues. Such an opportunity assists them to create and refine their understanding of the lawyer's role in assisting with dispute resolution, and more specifically, how they personally define themselves as professionals within that role. When asked

34 Michael King, Arie Freiberg, Becky Batagol \& Ross Hyams, Non-Adversarial Justice (The Federation Press 2009) at 231

35 Catherine Gage O'Grady (1997-1998) 'Preparing Students for the Profession: Clinical Education, Collaborative Pedagogy, and the Realities of Practice for the New lawyer' 4 Clinical Law Review 485 at 491.

36 Christine Parker \& Adrian Evans, Inside Lawyers' Ethics, (Cambridge University Press 2007) at 21-37.

37 Ibid 28.

38 Howard Lesnick (1992) 'Being a teacher of Lawyers: Discerning the Theory of My Practice' 43 Hastings Law Journal 1095 at 1099 . 
about the law students' role identity, one of the supervisors of the pilot project of the Monash Oakleigh Legal Service commented as follows:

By virtue of having three students from three different disciplines interview the client, I find that each student notices a different emphasis. They've all heard the same material, but sometimes they write down different and conflicting information and they have to rationalise it between each other - it's almost like a check and balance which can be a good thing or sometimes is confusing and requires further clarification. I think the students received a greater awareness of the bigger picture of each of their clients.

By having to rationalize their perceptions of the client's problem to students of other disciplines, the law student is confronted with the need to understand why they are focusing on particular aspects of the client's presentation (and not others). This requires students to develop self-insight and assists them to form an understanding of their own identity as legal professionals. ${ }^{39}$

Autonomy is an essential aspect of lawyering as the practice of law requires the making of judgments on an everyday basis. Ryan and Deci define autonomy as "action that is chosen; action for which one is responsible." 40 In a clinical environment, professional autonomy translates to student independence and self-direction. ${ }^{41}$ In a multidisciplinary setting, law students are forced to rationalise choices to their non-law peers and to take control of the legal aspects of the clients' problems. Working in a team requires a sense of responsibility to other members of that team and this responsibility enhances the notion that they must develop independence. As their team members are looking to them to take responsibility for certain important aspects of the client's matter, law students develop a sharp sense of self-direction and a feeling of responsibility for the choices they make, thus satisfying Ryan and Deci's definition. This awareness of the necessity to act autonomously can also be engendered in a conventional clinical legal education environment, but such students do not feel it as keenly as they are not required to justify their decisions or actions to other members of a peer team:

I learnt so much from my finance student, because we were together for three months. If I'd been with my social work student for that period of time, I think I would have learnt the same amount from her.

The practical knowledge that I've learnt is so valuable, not only legal, but finance and social work knowledge.

There is definitely 'bleeding 'between the disciplines. The good law students, those who are more empathetic and more attuned to treating a client, not a problem, pick up tips from the social work students and raise finances issues. - Comment of clinical supervisor.

However, it is worth the effort, as one student notes:

I can now issue spot areas really easily in which I think a client could benefit from a

39 Catherine Gage O'Grady (1997-1998) 'Preparing Students for the Profession: Clinical Education, Collaborative Pedagogy, and the Realities of Practice for the New lawyer' 4 Clinical Law Review 485 at 499.

40 Edward Deci \& Richard Ryan (1987)‘ The Support of Autonomy and Control of Behavior' 53 Journal Of Personality and Social Psychology) 1024

41 Ross Hyams (2008) 'On Teaching Students to 'Act Like a Lawyer': What Sort of Lawyer?' 13 International Journal of Clinical Legal Education 21 at 25. 
multidisciplinary approach just by flicking through a file or hearing a student discussing their clients with other students.

For this student, this skill obtained through working in the clinic supports Enos and Kanter's findings that students working in a multidisciplinary environment "see legal solutions as only one option among a multidisciplinary array of interventions." 42

Whilst in the workplace effective team work is viewed as an essential requirement of professional practice for social work students, according to Pockett ${ }^{43}$ limited attention is given to this aspect of practice in professional social work education. She challenges educators to give this element of best practice prominence in the social work curriculum. ${ }^{44}$ The incoming President of the Victorian Branch of the Australian Association of Social Workers - David Maxwell - recently affirmed his commitment to strengthening the professional position of social work in the contemporary scene by focusing his attention on an "increasingly challenging multidisciplinary environment." 45

The multidisciplinary clinic offers students from the social work discipline along with their law and finance counterparts this learning experience. Despite differences in discipline approaches to their work with clients, students are unified by a context that is based on social justice principles of providing service to those most in need. The legal circumstances in which clients present are "explored holistically taking into account the complexity of the social and financial concerns of each client". ${ }^{46}$ This opportunity enables students to learn much about the complexity of people's lives and the collaborative effort required to achieve change - but equally important and perhaps incidental to the main task "students learn to appreciate the unique skills and knowledge associated with each discipline, from both their peers and their supervisors." ${ }^{47}$ As one social work student highlighted very powerfully:

I learnt that legal practitioners and social work practitioners can have overlapping objectives in regards to working for the maximum benefit of clients. Although each profession is based on differing philosophical foundations, both can have the similar goal of working for the empowerment of the disadvantaged and vulnerable people of society.

Furthermore, there are many legal issues that evolve either directly or indirectly from entrenched social economic disadvantage, mental illness or some other form of oppression. I have learnt that the combined efforts of law and social work practitioners will multiply the capabilities of either profession working in isolation. A whole of person approach to client's problems involves the collaboration of professionals of various backgrounds and expertise.

42 V. Pualani Enos \& Lois H Kanter (2002-2003) 'Who's Listening? Introducing Students to Client-Centered, Client-Empowering, and Multidisciplinary Problem-Solving in a Clinical Setting' 9 Clinical Law Review 83 at 134.

43 Rosalie Pockett (June 2010) 'Interprofessional Education for Practice: Some Implications for Australian Social Work' Australian Social Work (63)(2),207

44 Ibid 208.

45 David Maxwell (2012) 'Incoming President's Report',1) ( 3) Social Work Connect 3.

46 'Hyams R, Brown G and Foster R (2013) "The Benefits of Multidisciplinary Learning in Clinical Practice for Law, Finance, and Social Work Students: An Australian Experience” 33 (2) Journal of Teaching in Social Work 159

47 Ibid 22 
Another student observed that:

Whilst together we had the ultimate goal of gaining the best outcome, how each discipline seeks to address the client's issues and how they perceive the issues was an eye opening aspect of working in the Multidisciplinary Clinic.

The value of this experiential learning for future practice was described by a social work student and supported by comments that follow from a finance student:

Working in the Multidisciplinary Clinic teams has given me a supported experience for future workplaces where I know I will come across multidisciplinary teams again.

To have a sense of workplace culture, to gain knowledge of effective team work and develop skills of investigating underlying issues.

The research findings of Eraut ${ }^{48}$ confirm that the two forms of informal learning reported by professional workers as most significant were the challenge of work itself and learning from other people. He concluded that the learning from such activities is largely implicit and difficult to explain. This research reinforced that working in groups with individuals who bring different expertise assists practitioners to both understand and utilise this expertise. ${ }^{49}$

Group learning strategies are an important tool in social work education. The team based learning available in a multidisciplinary setting facilitates co-operative learning amongst students. Research has shown the benefits of co-operative learning for students across a wide range of disciplines ${ }^{50}$ and social work educators agree. They suggest it fosters more effective critical thinking, improves student cohesion and respect for diversity amongst social work students. ${ }^{51}$ This research is supported by the comments of the social work students in the authors' clinic who commented about their learning:

'Every student approaches it in a different way and more heads are better than one! The more we include each other and contribute, the more the client benefits.

Other students identified the benefits as follows:

A positive would be working in a team and being able to discuss client's needs and issues between a group of you. If you have a long or tough interview with a client, it can be good to debrief with each other afterwards and especially with people who were in on the situation with you. It is also good to see that everyone can have different opinions about the same issue and to hear what other people thought and if you thought the same thing.

Whilst I have worked in team based workplaces before, the Multidisciplinary Clinic experience demonstrated to me how successful partnerships should work.

48 Michael Eraut(2011) 'Informal learning in the workplace : evidence on the real value of work-based learning (WBL),'Development and Learning in Organizations, (25)(5) 8-12.

49 Michael Eraut (2011) 'Informal learning in the workplace : evidence on the real value of work-based learning (WBL), 'Development and Learning in Organizations, (25)(5) 9.

50 D.W Johnson., \&Johnson,R.T. (1992) Creative controversy: Intellectual challenge in the classroom. Edina, MN:Interaction Book Co and R.E Slavin. (1995) Cooperative learning (2nded.). Boston, MA: Allyn \& Bacon in Judy Gillespie (Spring-Summer2012‘Enhancing social work education through team based learning’, (48) (2) Journal of Social Work Education 377.

51 Ibid at 377. 
Work based learning enables social work students to show evidence of their capacity to apply their academic knowledge to practice, as a precursor to learning directly from practice by critically reflecting on everyday tasks once they commence work. ${ }^{52}$ Mirabito suggests that field education in partnership with academics has traditionally served as a central strategy in the education of social workers. She acknowledges that, "Schools of Social Work are continually challenged to provide professional training which effectively prepares students" for the constantly changing and increasingly complex, practice context. New practitioners require a set of integrated social work skills that not only include the ability to provide direct clinical services to a diverse and disempowered client group but the skills to also negotiate demands within an agency, organisation or community; to communicate professionally both verbally and in writing, as well as conduct relevant research and program evaluation as required. ${ }^{53}$ Political skills in managing in difficult environments, inter or multidisciplinary teams, working collaboratively and taking up leadership roles to develop services and programs are also recognised as necessary skills.

The ability to maintain a strong social work identity in the face of encroachment from other professions is also a current requirement for the new practitioner. Much of this learning is often developed during field education experiences in incidental and spontaneous ways that are context dependent and not always predictable. ${ }^{54}$ Developing a sense of professional social work identity can be particularly difficult for new social work graduates who work in a multidisciplinary environment, according to Seden and McCormick. ${ }^{55}$ Social workers that place clients at the centre of their practice and who can identify the influence of social context and use a holistic approach based on a trusting relationship, are encouraged to bring these skills to influence multidisciplinary settings. ${ }^{56}$

Such workplace contexts are where not only professional practice but professional identities are developed. ${ }^{57}$ Davis, Gordon and Walker noted that professional identity development relies on the building of confidence from reflecting on knowledge and learning through practice - a confidence to challenge, negotiate and provide professional assessments of value. ${ }^{58}$ Agllias reported in her findings that new social work graduates often struggled with role conflict, clarity and value conflicts. ${ }^{59}$ She highlights the increasingly complex contemporary work environment where the role of the social worker may be overlooked or misunderstood. Social work may be

52 Roger Davis, Jean Gordon and Gill Walker Chapter 20 'Learning in practice: Some reflections on the student's journey', in Janet Seden, Sarah Matthews, Mick McCormick, Alun Morgan Professional Development in Social Work (Routledge, Hoboken, 2010).

53 Diane M. Mirabito (2011) 'Educating a New Generation of Social Workers: Challenges and Skills Needed for Contemporary Agency-Based Practice' Clinical Social Work Journal 1-11 Springer link 10.1007/s10615-011-0378.

54 Ibid 1,5

55 Janet Seden and Mick McCormick, Chapter 24 'Caring for yourself, being managed and professional development' in, Janet Seden, Sarah Matthews, Mick McCormick, Alun Morgan Professional Development in Social Work (Routledge, Hoboken, 2010) 171-177.

56 Ibid 175-176.

57 Jan Fook Chapter 3 'Beyond reflective practice Reworking the 'critical' in critical reflection' in Beyond Reflective Practice New approaches to professional lifelong learning Eds. Helen Bradbury, Nick Frost, Sue Kilminister and Miriam Zukas (Routledge, Oxon,2010) 49.

58 Davis,Gordon and Walker above n 53.

59 Kylie Agllias(2010) 'Student to Practitioner : A Study of Preparedness for Social Work Practice' Australian Social Work (63)(3) 345-360. 
rendered powerless as tasks perceived as social work are performed by other professionals. ${ }^{60}$ Interestingly, the social work students in the multidisciplinary clinic found holding onto their identity a challenging task. Some social work students may have been intimidated by being in the law students' "realm." Professional status and power differences were observed. However, the consequent learning opportunity is also highlighted by the comments of students.

"Law students in a legal service may dominate the way in which interactions between the client and students take place"

"At times it could feel as though the social work component of the Multidisciplinary Clinic was peripheral to that of the law work"

"It can be hard to voice your perspective, but that is something that can be worked around with time."

"There is a bit of a hierarchy"

"In terms of viewing myself as a social work practitioner, one thing all of us achieved is our own sense of resilience."

Developing the skills and confidence to influence workplace culture in order to advocate for and provide responsive and effective social work service is an excellent learning opportunity offered to social work students in the multidisciplinary setting of a legal service, where the core business is legal and where higher status professions like law lead. There is great value in a pedagogical focus on organisational skills and strategies for social work practice in inter and multidisciplinary settings that include legal or health care services. ${ }^{61}$ In these workplaces in particular, social work students are required to develop skills in negotiation, collaboration, leadership and interpersonal communication to ensure psycho social issues are voiced and political climates are understood and influenced for the benefit of the client. Skills in effective communication with professional disciplines who command more power and influence is a necessity for contemporary social work practice. ${ }^{62}$

\section{What learning outcomes should we expect from an MDC?}

In addition to practical skills such as interviewing, negotiation, letter writing, advising and document drafting which are expected outcomes of clinical education, there are a number of other learning outcomes which can be perceived, measured and assessed from multidisciplinary clinical experience. Apart from the acquisition of a number of practical professional skills, there are some less tangible learning outcomes which can be derived from a multidisciplinary environment which are a direct result of this unique form of learning. This is not to say that such skills cannot be obtained elsewhere in a vocational university curriculum - however, a multidisciplinary clinic is an excellent environment to nurture a particular set of skills that are necessary for graduates to operate effectively in today's practice setting. The first of these skills is that of self-reflection. It has been stated before that the clinical environment is the perfect laboratory for action and

60 Ibid 354.

61 Diane M. Mirabito above n 54.

62 Ibid 6. 
reflection. ${ }^{63}$ One of the prerequisites for an effective pedagogy of reflection is that students must be placed in situations which are outside of their normal range of experiences. ${ }^{64}$ It is fair to say that a multidisciplinary clinical environment will certainly present challenges to most students which are far outside of their previous educational experiences. Students can be encouraged to develop and refine their reflections of their multidisciplinary clinical education by way of reflective journals or learning diaries ${ }^{65}$ which can be submitted to their clinical supervisor, discussed and (if desired) assessed. ${ }^{66}$ The skill of self-reflection is essential to becoming a well-rounded professional and in striving to become what Schön describes as the "reflective practitioner" 67 - adult learners who reflect on their experiences for the purposes of self-evaluation and improvement. As one student commented:

"The process of introspection has helped me to reconceptualise the role of a lawyer as more than just a legal advisor. I now understand that a good lawyer needs to play the role of educator, planner and counselor."

Critical reflection learning processes that start with individual experience and include social contexts of professional practice such as workplaces, 'professional cultures, social, political and cultural contexts' ${ }^{\prime 68}$ are encouraged in social work education - especially clinical practice. This involves examining assumptions that may be implicit or incidental to a task, but significant for practice learning. This reflection is considered critical if it enables 'an understanding of the way socially dominant assumptions' ${ }^{69}$ restrict so that more empowering practices may be chosen. Fook encourages professional lifelong learning and the role of critical reflection processes. ${ }^{70}$ She also sees the importance of people developing "a sense of their own professionalism and professional practice" 71 separate from workplaces. Developing an understanding of how one's fundamental values impact on the construction of professional identity, which is then translated into professional practices, may occur intentionally or incidentally through critical reflection. Workplace cultures can be very powerful and the importance of educating students to be alert to organisational values is not to be underestimated, according to Fook. ${ }^{72}$ In the authors' opinion, there is no better "laboratory" for this to be nurtured than in the multidisciplinary service delivery environment. The students who were surveyed for this paper were very aware of these issues:

"I have learnt to analyse and be critical of client stories as they do not always tell the truth or act in their best interest. Think a bit like a lawyer."

63 Jacqueline St. Joan, (2001) 'The Clinic as Laboratory: Lessons from the First Year of Conducting Social Research in an Interdisciplinary Domestic Violence Clinic' 47 Loy. L Rev 317.

64 Richard Rogers, (2001) 'Reflection in Higher Education: A Concept Analysis' 26(1) Innovative Higher Education 37 ,

65 Ross Hyams, (2010) “Assessing Insight: Grading Reflective Journals in Clinical Legal Education” 17 James Cook University Law Review 25.

66 Id.

67 D Schön, The Reflective Practitioner: How Professionals Think in Action (New York, 1983).

68 Jan Fook above n 58 at 49

69 Ibid 40.

$70 \operatorname{Ibid} 38$.

71 Ibid at 39 .

72 Id. 
"Lawyers aren't all bad, which I believe is a big misconception."

"I have learnt about the assumptions people make about social work."

"Taught me how to engage in a working environment where everyone may not agree on the best course of action regarding a client and how that has to be negotiated."

"I have learnt more about people in general (clients, co-workers and friends) and about human interaction and development than in my life and degree thus far."

This purposeful and structured way of achieving insight links in with the concept of autonomy previously discussed in this paper. As law students develop insight into their clinical experiences, they form a self-view of their lawyering style which will be shaped by their interactions with their non-law peer team members. This helps to reinforce their budding notions of autonomy and independence, as noted by this student's learning:

"Law is not for the faint hearted and I need to be mindful of my clients and their needs, as ultimately these will make me happier in my chosen profession."

The pedagogy of a multidisciplinary clinic also leads to law students forming an understanding (perhaps for the first time) of social justice issues. This exposure to a social justice agenda is enriched by interactions with peers from other disciplines (such as social work students) who, because of the very nature of the discipline from which they derive, often have a more sophisticated understanding of social justice at the outset of their clinical experience. Rand points out that social work students operate from the perspective of an "empowerment model" basing their interventions in their clients' lives on whether it will improve social justice for the client and the community. ${ }^{73}$ By contrast, law students often perceive the legal system from a positivist construct and concentrate on understanding and applying existing law, rules and processes. As a result of their legal education, they often have a form of legal myopia - focusing on the law "as is", rather than the possibilities for reform and change. Rand further suggests that during their legal education, law students may be exposed to some awareness of social justice issues, but that pedagogy in legal education generally does not approach the social justice agenda in a creative or structured fashion. ${ }^{74} \mathrm{He}$ contends that law students must form a perception of social justice "that is both strongly held and operational". ${ }^{75}$ Certainly, being challenged by peers in a multidisciplinary team from disciplines such as social work with a strong social justice agenda will assist in this process. These law students highlight their operational learning:

"Often, there are underlying financial and mental health problems. This meant helping clients meaningfully needed to involve more than just focusing upon the legal issue they had presented with."

"Every time I went to meet a client with a finance or social work student, I felt better equipped to resolve any problems that could potentially arise.

73 Rand, S.(2006) 'Teaching Law Students to Practice Social Justice: An Interdisciplinary Search for Help through Social Work's Empowerment Approach’ 13 Clinical Law Review 459 at 484.

74 Ibid 463.

75 Id. 
"Law is more than just statutes and High Court Judgments but it also deals with people who have issues beyond the black and white legal problem."

"It was refreshing to see how uncompetitive, caring and approachable the social work students were."

In tandem with an increased perception of social justice issues, the pedagogy of multidisciplinary clinic sharpens law students' ethical awareness of the lawyering role and their understandings of professional responsibility. Evans and Hyams note that clinics have not only the opportunity, but the responsibility to provide training in these areas ${ }^{76}$ as there are minimal opportunities in the traditional legal education curriculum to successfully instill a sense of ethical consciousness in law students ${ }^{77}$ in an engaging and participatory fashion. Clinical legal education, especially a multidisciplinary environment, constantly challenges students in this area as they are forced to deal with ethical issues on an almost daily basis in the context of attempting to obtain the best possible outcomes for their clients. Indeed, it is the very random nature of clinic which provides the various opportunities to deal with the spontaneous challenges of ethical issues in an immediate practice setting. ${ }^{78}$ When an ethical issue is raised in the context of casework, law students must not only consider the published professional rules of conduct, but their own ethical framework, social justice issues and the impact of their conduct on the community. ${ }^{79}$ Working in a multidisciplinary team, law students' awareness of their personal and professional ethics are sharpened and placed under the spotlight of scrutiny from their supervisors and peers alike. They are challenged by the twists and turns of the legal system in its operation in the social milieu and they must justify their decisions and motivations to their non-law peers. Parker and Evans refer to this process as 'values awareness' ${ }^{\prime 0}$ and suggest that legal education can challenge, change and form an early understanding of ethical values in law students which may ultimately lead to better career choices and more satisfactory working lives. ${ }^{81}$

Our research indicated that social work students, like the law students, experienced and learnt from ethical dilemmas in their multidisciplinary practice. Ethical principles and values such as confidentiality and taking a client centred approach appeared to be similar for both the law and social work students but were not mentioned by the business economic students. Whilst law places a priority on the client's instructions, the social worker students realised that the best interests of the client and community were most highly valued in their interventions. Similarly, the primary focus of law may often appear to be an overriding duty to the court, or the law itself, whilst for social workers, it is more obvious that clients are of greatest significance. This did result in some value differences and the social work students had to reflect critically on their interventions on a number of occasions, where, for example, there was the threat of further domestic violence, child

76 Adrian Evans \& Ross Hyams (2008)“Independent Evaluations of Clinical Legal Education Programs: Appropriate Objectives and Processes in an Australian Setting" 17 Griffith Law Review 52 at 69

77 Adrian Evans and Josephine Polermo (2006) 'Preparing Future Australian Lawyers: An Exposition of Changing Values Over Time in the Context of Teaching About Ethical Dilemmas' 11 (1) Deakin Law Review 103.

78 Mary Anne Noone \& Judith Dixon(2001) 'Teaching Towards a New Professionalism: Challenging Law Students to Become Ethical Lawyers 4(2) Legal Ethics 127 ay 135.

79 Ibid 143.

80 Christine Parker \& Adrian Evans (2007) Inside Lawyers Ethics, Cambridge University Press at 254.

81 Id. 
abuse or criminal behaviour. As clients attend the service for legal reasons, the social work students were cautious about the extent to which they might challenge a law student on an issue of concern. They were aware of the importance of balancing their concerns about a client with the aim of team harmony and acceptance by peers. ${ }^{82}$ Cooper notes that social work is about "the judicious and ethical use of power and authority and the accompanying responsibilities." 83 Learning to assess a personally challenging situation of a client, whilst maintaining a constructive working relationship, increased and tested the ethical awareness for all students at the legal service. ${ }^{84}$

Agllias concludes from her research that social work graduates need the support of social workers with experience to reflect and challenge boundary conflicts and unethical practices in the workplace. ${ }^{85}$ Eraut's findings confirm that support and feedback are critical factors for "confidence, learning, retention and commitment." 86 It was found that the quality of this support and feedback as well as appreciation for work completed, impacted on commitment to work. ${ }^{87}$ At the multidisciplinary clinic where students are expected to perform and achieve outcomes for clients, students quickly learn about the importance of quality supervision. Supervision is available to not only social work students but all the students and it was acknowledged by most students as supportive, collaborative and valuable. The other opportunity available to students and supervisors is to engage in research to explore the impact of this model of practice on students, supervisors and clients.

Undertaking empirical research on the pedagogy of multidisciplinary student learning environments ${ }^{88}$ is a goal of the program but not easily achieved given the business of students and supervisors attending to the complex needs of the clients that present. A first attempt at a qualitative study to develop a better understanding of students' perspectives on the influence of the multidisciplinary clinic on their learning and future practice has just commenced. During the last semester of 2012, as students from business economic, law and social work who participated in the multidisciplinary clinic were close to departing; they were emailed a questionnaire by the social work supervisor. A pre and post questionnaire could be introduced in the future to more accurately measure the impact of the clinical experience. Structured and semi structured interviews would explore more deeply the views of students. However, limited time and resource constraints have meant that, thus far, only a questionnaire could be undertaken. The questionnaire provided students with the opportunity to voice their opinions about the program. The forty six students invited to participate were completing their placements and reflecting on their experiences was encouraged using a brief questionnaire. Sixteen were from the law faculty, sixteen were business economic students and fourteen were social work students. An explanatory statement was forwarded as well as a consent form detailing the research title, voluntary nature of participation and confidentiality provisions, for participants to sign if they chose to participate.

82 Kylie Agllias above n 60.

83 Barry Cooper Chapter 3 'Criticality and reflexivity Best practice in uncertain environments' in Janet Seden, Sarah Matthews, Mick McCormick, Alun Morgan, Professional Development in Social Work (Routledge, Hoboken, 2010).

84 Ibid 20.

85 Kylie Agllias above n 60 at358.

86 Michael Eraut (2011) above n 49.

87 Ibid 11

88 Kylie Agllias above n 60 at 357. 
The questions asked were open ended, designed by the social work supervisor to enable students to reflect on the following: what they had hoped to learn and what they actually learnt; both the positive and negative aspects of their experience; how the multidisciplinary approach had helped (or not helped) to meet the needs of clients; the impact of their learning experience on their future practice; and an opportunity to contribute any other comments which most students completed. Fifteen out of 16 social work students completed the questionnaire; three out of sixteen law students and three students from the Faculty of Business and Economics participated in the research. The high social work student participation may have been a result of their supervisor requesting participation. The other students may have felt less compelled to participate given it was not part of their assessment requirements and assessment was a high priority towards the end of their placement at the multidisciplinary clinic. An interview approach may also have resulted in an increased participation rate.

Themes were identified and summarised to contribute to further understanding and development of the learning opportunities facilitated by a multidisciplinary setting. A more refined set of research questions that explores the influence of social justice values and principles as well as models of supervision in the multidisciplinary context is also possible in the future.

Themes arising from the surveys received to date from the law, social work and finance students include the value of learning to transfer academic knowledge into practice. Students noted their improved investigative and organisational skills as well as the importance of being thorough and detail oriented. They identified writing skills; insight into the contributions of different disciplines; team work and collaboration as relevant learning. Communication skills such as negotiation, leadership and assertiveness were also skills acquired. Observing social justice in practice was noted, as was the confidence to holistically meet the needs of complex clients. Some students highlighted an increased self-awareness and insight into the value of supervision and supportive peers. Learning about workplace culture, policies and legislation; developing practice autonomy; and professional identity development were among the outcomes acknowledged by all the students from the multidisciplinary experience.

All the students from the three disciplines highlighted the value of effective teamwork in multidisciplinary practice. The finance students valued the opportunity to be exposed to 'real life situations'. Law students acknowledged a preference for working with "those who really need my help rather than dealing with company mergers and never meeting a client" and the importance of a 'holistic' approach to be effective. The unique supportive learning environment was noted by both law and social work students. The importance of supervision for support and guidance was noted by social work students who also highlighted the value of input from other discipline supervisors to their learning. More than half of the social work students highlighted the value of the legal knowledge learnt for their future work with clients. Two students expressed their intention to undertake law degrees and two identified working in the legal context as a future goal.

Some of this learning occurred incidentally to providing services to clients in need. However, it is still early days in the life of the multidisciplinary clinic and the qualitative methodology and small sample size limit the ability to generalise from these findings. However, it can be noted that students identified their own professional practice learning as well as generic skill development necessary for all practitioners in the workplace. Social work literature reinforces the need for graduates to bring a broad repertoire of integrated skills beyond the clinical to meet current 
practice demands. ${ }^{89}$ In a competitive employment market, it is expected that all professional workplaces would demand similar employability skills, which is an important outcome of this experience based pedagogy.

\section{Can we measure these outcomes?}

There has been, and will continue to be, much debate regarding assessment in clinical programs. ${ }^{90}$ Much of this debate surrounds the dispute as to whether a pass/fail or graded regime is appropriate for the assessment of clinical work. ${ }^{91}$ There has also been debate as to whether it is appropriate (or even possible) to assess the acquisition of 'professional responsibility' 92 and how feasible it is to assess insights demonstrated by student in reflective journaling tasks. ${ }^{93}$ It is not necessary to repeat these arguments here - however, the authors believe that it is both possible and valuable to measure the learning outcomes of a multidisciplinary clinic, with the aim of providing students with useful formative and summative feedback.

Formative feedback comes in many modes and can be informal (such as brief casual discussions with students as to their responses to clients or the way they drafted a document) and formal (for example, scheduled file review meetings or mid semester appraisals) or a mixture of both. Summative assessment can be by way of a written case study or reflective essay. However, Stefani notes that assessment is not just about measuring whether students can deliver a 'product' at the conclusion of the learning period, ${ }^{44}$ but should also be about assessing the learning process itself. This supports the notion that the ongoing assessment of the acquisition, development and refinement of emotional and narrative intelligences (often demonstrated via the reflective journaling process) can be a useful vehicle of student learning.

Irrespective of the tools that are used for assessment, it is imperative that the multidisciplinary clinic actually assesses the learning outcomes promulgated by the clinic. This was pointed out by Stuckey in the incredibly helpful CLEA Best Practice Report:

"Outcomes should be measurable. It is self-defeating to state an outcome which cannot be assessed. At the same time, it is important not to be bound by the expectations of objective decimal place accuracy. In this context "measurable" means a general judgment of whether students know, think, and can do most of what we intend for them". 95

If the expectations on students and the learning outcomes of the clinic are made explicit, students can be assessed on practical skills such as interviewing, advising, file management and letter writing

89 See, for example, Diane M. Mirabito (2011) above n 54.

90 See, for example, Simon Rice, 'Assessing - but not Grading - Clinical Legal Education' (2007) Macquarie Law WP 16; Ross Hyams, (2006) 'Student Assessment in the Clinical Environment - what can we learn from the U.S. experience?' 10 International Journal of Clinical Legal Education 77; Stacy Brustin\& David Chavkin, (1997)'Testing the grades: Evaluating Grading Models in Clinical Legal Education’ 3 Clinical Law Review 299; Evans \& Hyams, above n 77.

91 Id.

92 Evans \& Hyams, above n 77 at 71.

93 Hyams, above n 42.

94 Lorraine Stefani “Assessment in Partnership with Learners" (1998) 23(4) Assessment Eु Evaluation in Higher Education 339 at 344.

95 Roy Stuckey et al. CLEA Best Practice Report (2007) Clinical Legal Education Association U.S.A at 49. 
as well as the less tangible skills such as reflection, professionalism, creativity, collaboration and teamwork. Many of these less tangible skills are also learnt via the vehicle of incidental learning and can be also be reliably assessed. Assessment rubrics which identify both practical and less tangible skills can be created which are provided to the students at the outset of their placement in the clinic, and formative feedback provided to students as to whether they are being successful in attaining the skills and qualities expected of them. An assessment rubric of this sort needs to be comprehensive and versatile, enabling students to obtain marks in various areas of both the practical and less abstract skills being taught intentionally and acquired by students in their participation in the clinic. ${ }^{96}$ This is quite a burdensome task for clinical educators, as it requires much commitment to the assessment regime in terms of observation of the students, appropriate scrutiny and analysis of their performance ${ }^{97}$ but the outcomes for the students of detailed, timely and continuous feedback which is linked to the learning outcomes of the clinic greatly enhances their learning experience.

Social work educators are interested in promoting good learning outcomes driven, according to McDonald, ${ }^{98}$ by a responsibility for the "well-being of a student's future clients." 99 Social work literature, she suggests, describes student self-efficacy in terms of client outcomes and students' readiness for practice. Continuous improvement in skills education to increase student self-efficacy is recommended. Promoting skills in "critical analysis and problem solving within a framework of ethicality" 100 is also supported. Pocket emphasises the need to prepare social work students with the skill, insight and critical ability to deal effectively with the uncertainties of practice in the postmodern world. ${ }^{101}$ These skills are assessed during field placement by clinical educators against relevant learning areas. All learning - observed, documented, reported and practiced, structured or incidental - is constructively reviewed for discussion during supervision and placement reports provided to the individual student as feedback and evidence of their experiential learning for practice.

Team based learning evident in multidisciplinary settings assists students to investigate, discuss and explain the best approach to addressing the complex world of professional practice. ${ }^{102}$ Learning about the dynamics of working with others to achieve shared goals involves each student taking some responsibility for outcomes. This learning may develop at different stages for each student. ${ }^{103}$ Ensuring students are assessed fairly and are held accountable for their contribution requires feedback to both individuals and teams about their performance that is frequent and timely. Assessment of outcomes can include evaluations of student engagement, supervisor satisfaction as well as student attainment of the specific knowledge and skills necessary for practice. Research to date demonstrates that the learning outcomes for students in the team based

96 Ross Hyams (2006) "Student Assessment in the Clinical Environment - what can we learn from the U.S. experience?" 10 International Journal of Clinical Legal Education 77 at 87.

97 Id

98 Catherine McDonald (2007)“This is Who We are and This What We Do: Social Work Education and Self Efficacy" (60) (1) Australian Social Work, 83.

99 Ibid 85.

100 Catherine McDonald above n 106 at 85.

101 Rosalie Pockett above n 44.

102 Judy Gillespie above n 48

103 Rosalie Pockett above at n 44 at214-215. 
multidisciplinary clinic are significant. ${ }^{104}$

\section{Conclusion - implications for the future}

To a large extent, our multidisciplinary clinic it still in its pilot phase. The supervisors are constantly learning along with the students. However we have identified, through this research, that incidental learning that has been taking place and the value derived by the students therefrom include the micro skills needed for practice; learning about student preferences for contexts of practice; working with other professionals from their own and different disciplines as well as what approach is most effective with their clients. We believe that we now have some opportunities to capitalize on these benefits. We need to find ways to maintain and nurture an incidental learning environment in order to improve proficiency and transfer of learning in the clinical setting. Part of doing this is simply awareness of the value of incidental learning. It also includes the provision of opportunities for students to indulge in what Harrison Owen refers to as "spontaneous corridor conversations" 105 - this requires "open space technology"106, that is, not only informal areas for students to work and socialize, but informal time for them to do so. Inevitably, providing both this space and time may require changes in workroom geography and in timetabling client interviews, seminars and other formal learning times. It may mean a reduction in formal teaching time or in the way this is delivered, in order to maximize informal learning opportunities.

Clinical educators can assist students to link their theoretical learning to workplace practice. This significant learning may be informal or incidental and developed in collaboration with teams of professionals from different disciplines. Learning to work with other disciplines in a team context is a particularly relevant skill for social work students, who may find their social work role in the workplace not always clearly defined. ${ }^{107}$ Shared learning experiences (as noted by a number of students in this research) have many benefits that often occur incidentally. Most importantly, this includes an increased understanding of the motives and intentions of other professionals, as well as the cultures that influence their practice.

The "growth and transformation" of students into professionals occurs from learning from experiences that may be made transparent or more evident to students during the practice of their micro skills in a real life context. Some of this learning is incidental and uniquely dependent on the individual student and their experience of the practice context. Such educational contexts are found in inter and multidisciplinary practice settings. ${ }^{108}$ According to research conducted by Enos, Kehrhahn and Bell, "Proficiency is the result of informal learning." 109 Finding opportunities for learning naturally where support and feedback are available was a critical finding by Eraut. ${ }^{110}$

104 Judy Gillespie above at n 52 at 378, 382.

105 Owen H (1997) Open Space Technology: A users guide. San Francisco: Berrett-Koehler Publishers $106 \mathrm{Id}$.

107 Rosalie Pockett above n 44.

108 J Lave \& E Wenger (1991) Situated Learning: Legitimate Peripheral Learning. In R Pea \& JS Brown (Eds)

Learning in Doing: Social, Cognitive and Computational Perspectives Cambridge University Press pp $121-122$.

109 M Enos, M Kehrhahn\&A Bell (2003) 'Informal Learning And The Transfer Of Learning: How Managers

Develop Proficiency' 14 (4) Human Resource Development Quarterly 369

110 Michael Eraut 'Informal learning in the workplace: evidence on the real value of work-based learning (WBL),'

Development and Learning in Organizations, (2011) Vol 25 Iss:5, pp.8-12. 
Our early research from the multidisciplinary setting previously discussed also supports these findings and provides student perspectives on the value of their experiential learning. As such, the results of this research and our new understandings of informal learning provide clinical educators with challenges in order to maximize the incidental learning benefits students receive from a multidisciplinary clinical environment. Clinical educators have a responsibility to actively engage students in interactive and innovative initiatives. Acknowledging the value of incidental learning for all students, no matter what the discipline, is an important factor in ensuring education prepares graduates well for the increasingly complex workplaces of today. 
